\section{Effects of Light Quality on Vegetative Cutting and In Vitro Propagation of Coleus (Plectranthus scutellarioides)}

\author{
Keun H. Cho', Veronica Y. Laux, and Nathan Wallace-Springer \\ Department of Environmental Horticulture, University of Florida, \\ Gainesville, FL 32611
}

\author{
David G. Clark \\ Department of Environmental Horticulture, University of Florida, \\ Gainesville, FL 32611; and Plant Innovation Center, Institute of Food and \\ Agricultural Sciences, University of Florida, Gainesville, FL 32611
}

Kevin M. Folta

Department of Horticultural Sciences, University of Florida, Gainesville, FL 32611; and Plant Innovation Center, Institute of Food and Agricultural Sciences, University of Florida, Gainesville, FL 32611

\section{Thomas A. Colquhoun}

Department of Environmental Horticulture, University of Florida, Gainesville, FL 32611; and Plant Innovation Center, Institute of Food and Agricultural Sciences, University of Florida, Gainesville, FL 32611

Additional index words. narrow-bandwidth, propagation, vegetative cuttings, shoot tip culture, chlorophyll

\begin{abstract}
Coleus (Plectranthus scutellarioides) is an attractive and popular ornamental plant with propagation mainly achieved through vegetative cuttings. For commercial purposes, it is of interest to enhance the speed of establishment while maintaining high quality. Light quality has been shown to influence adventitious root development, so these experiments examined the effect of narrow-bandwidth light treatments on root growth and overall plant quality for seven coleus cultivars with vegetative cuttings in potting soil and one cultivar with shoot tip in vitro cultures onto Murashige and Skoog (MS) agar medium. During the 28 days of the propagation period, the cuttings grown under narrowbandwidth red light $(R ; 663.4 \mathrm{~nm}$ at peak) more than doubled in the adventitious root number compared with those under blue light $(B ; 445.7 \mathrm{~nm}$ at peak) and green light $(G$; $530.0 \mathrm{~nm}$ at peak) in five cultivars. $R$ light also increased fresh weight of the cuttings by $\mathbf{5 5 . 6} \%$ more than $G$ light. In comparison, the cuttings grown under $G$ light yielded significantly lower root and shoot dry mass than other light treatments. $R$ light cuttings showed more dry mass content $(9.63 \%)$ than those under white light $(W ; 437.4 \mathrm{~nm}$ and $559.5 \mathrm{~nm}$ at peak) and $\mathrm{G}$ light $\left(7.85 \%\right.$ and $5.86 \%$, respectively). A positive correlation $\left(\boldsymbol{R}^{2}\right.$ $=0.598, P<0.001$ ) was found between the formation of adventitious roots and gained fresh weight of cuttings. $R$ light made the reddish color of leaves significantly stronger in most cultivars, whereas the cuttings exposed to $G$ light became less vivid compared with other light conditions. When the shoot tips were propagated in vitro onto MS medium, $R$ light treatment initiated the root development more rapidly than other lights, with significantly greater rooting rate $(20.0 \%$ and $63.6 \%$, respectively) at day 5 and 10 . The shoot tips under $R$ light also formed significantly more roots (12.3 per cutting) than those grown under narrow-bandwidth $B$ light (5.8 per cutting). The shoot tips showed browning at an early stage and newly emerged leaves grew very compactly under $B$ light. The combination of red and green light $(R+G)$ increased more than twice as much roots and dry mass compared with $W$ light. In addition, the $R+G$ light led to morphological changes, including larger leaves and longer petioles and internodes than those in other light treatments. The exposure to $R+G+B$ and $B$ light made the shoots very compact for the 28 days of in vitro culture period and significantly increased the chlorophyll contents resulting in dark green leaves.
\end{abstract}

Vegetative cutting is an indispensable propagation technique for the mass production of ornamental annuals, perennials, herbs, shrubs, trees, and foliage plants. This method offers substantial advantages of maintaining identical phenotypic traits (colors, volatiles, growth rates, yields, or disease resistances) et al., 2014; Daud et al., 2013). Environmental factors such as adequate mist interval, relative humidity, temperature, light, and ambient air flow should be carefully considered for the stable formation of adventitious roots, which is essentially required to pro- from selected species or cultivars (Bellini duce healthy, independent plants (Christiaens et al., 2015). The development of adventitious roots also has been shown to be auxin mediated and light dependent. Light acts antagonistically with endogenous auxin (indole-3-acetic acid) movements in plant tissue, which stimulates the adventitious root development (Ahkami et al., 2013; Sorin et al., 2005). The auxin produced in shoot apex basipetally transports down the plant stem and accumulates at the base of cuttings to initiate adventitious roots (Christiaens et al., 2016). Perception of light quality by plants can induce changes in gene expression and hormonal regulation resulting in morphological developments (Pedmale et al., 2016). Plants capture the wavelengths of light $(\approx 380-750 \mathrm{~nm})$ to convert light energy into chemical energy (photosynthesis) and as environmental cues to control specific behaviors (photomorphogenesis) (Gautam et al., 2015; Morrow, 2008; Peñuelas and Filella, 1998). This occurs through the activation of a discrete set of photoreceptors - the phytochromes, cryptochromes, phototropins, and other light-oxygen-voltage domain proteins and UV RESISTANCE LOCUS 8-which detect and respond to changes in quality, quantity, and the photoperiod of light (Batista et al., 2018; Huché-Thélier et al., 2016; Moni et al., 2015; Pedmale et al., 2016).

Red light (650-660 nm) has been reported to enhance adventitious root formation in grapes (Poudel et al., 2008), Ficus benjamina (Gabryszewska and Rudnicki, 1994), and Protea cynariodes (Wu and Lin, 2012). In Arabidopsis, phytochrome A and B (PHY A and PHY B) mediate the positive phototropic responses to red light, and these two photoreceptors are involved in the modification of local endogenous auxin levels (Bellini et al., 2014). The effects of blue light on rooting are sometimes inconsistent. Lim and Eom (2013) observed very rapid root formation from sweet basil stem cuttings under blue light $(460 \mathrm{~nm})$ in 2 weeks. However, superbright blue light inhibited root formation in strawberry plantlets (Nhut et al., 2003). In grape in vitro culture, root development was reduced in response to blue light ( $\mathrm{Li}$ et al., 2017). Light-emitting diodes (LEDs) make it possible to combine different wavelengths so that the customized mixture of lights may promote more desirable growth characteristics for species and cultivars (Batista et al., 2018; Massa et al., 2008). Enhancement of rooting, leaf color transition, and high-quality seedling growth could be achieved with optimum operation of wavelength (Daud et al., 2013; Fan et al., 2013a; Kim et al., 2004a; Olschowski et al., 2016; Wollaeger and Runkle, 2014).

Coleus (Plectranthus scutellarioides) is an appreciated ornamental plant because of its significant genetic variability. Because its propagation is achieved by rooting vegetative cuttings, it was of interest to test the hypothesis that narrow-bandwidth light conditions could improve the rooting efficiency over standard white light conditions. Seven commercial 
coleus cultivars were cutting-propagated in soil under five different wavelength treatments. Also, coleus shoot tips from one cultivar were rooted onto MS medium in vitro under various light treatments including single or mixed wavebands, compared with cool-white fluorescent (CWF) treatment. It was shown that different narrow-bandwidth light treatments influenced adventitious rooting, shoot growth, and leaf color transition of coleus plants grown from vegetative stem cuttings, as well as establishment of in vitro shoot tip cultures. These experimental results demonstrate that propagation of coleus may be hastened by application of narrow bandwidth light.

\section{Materials and Methods}

Installation of various LEDs in a temperature-controlled room. Light treatments were generated using custom-built LED arrays [Solid State LED Lighting; Pampanga, Philippines (Zhang et al., 2011)]. The light spectra (Fig. 1) were obtained with a StellarNet spectroradiometer and visualized on SpectraWiz software (Stellar Net Inc., Tampa FL). Four light conditions were blue [B; $445.7 \mathrm{~nm}$ at peak, $18.3 \mathrm{~nm}$ of full width at half maximum (FWHM)], green (G; $530.0 \mathrm{~nm}$ at peak, $40.0 \mathrm{~nm}$ of FWHM), yellow (Y; $601.9 \mathrm{~nm}$ at peak, $79.5 \mathrm{~nm}$ of FWHM), and red (R; $663.4 \mathrm{~nm}$ at peak, $18.8 \mathrm{~nm}$ of FWHM). Also, one more light was modulated, having peaks in the blue and yellow $(437.4 \mathrm{~nm}$ at peak, $19.4 \mathrm{~nm}$ of FWHM and $559.5 \mathrm{~nm}$ at peak, $126.5 \mathrm{~nm}$ of FWHM), which are perceived as white light (W) by the human eyes. These five light treatments were tested for effects on coleus cutting propagation in soil. Each light treatment was set to a fluent rate of $100 \mu \mathrm{mol} \cdot \mathrm{m}^{-2} \cdot \mathrm{s}^{-1}$. The same light treatments were assessed for the effects on shoot tip propagation in vitro, compared with CWF lamps (T12, 40W, 4100K; Philips Co., Amsterdam, The Netherlands). The effects of combined treatments, $\mathrm{R}+\mathrm{G}$ (mixture of $\mathrm{R}$ and $\mathrm{G}$ light, 80:20) and $\mathrm{R}+\mathrm{G}+\mathrm{B}$ (mixture of R, G, and B light, 40:20:40) also were assessed.

Vegetative cutting propagation in soil for seven coleus cultivars. Seven coleus cultivars grown in an experimental greenhouse at the University of Florida, 'Abbey Road (AR)', 'Lime Time (LT)', 'Limon Blush (LB)', 'Oxford Street (OS)', 'Velveteen (VL)',

Received for publication 23 Jan. 2019. Accepted for publication 1 Mar. 2019.

This work was supported by grants from the US Department of Agriculture (USDA)-Agricultural Research Service Floral and Nursery Research Initiative, USDA-National Institute of Food and Agriculture, the National Horticulture Foundation, the Fred C. Gloeckner Foundation, and American Floral Endowment.

Authors' contributions: K.H.C. analyzed the data and wrote the manuscript. V.Y.L. and N.W.S. conducted all the experiments. D.G.C., K.M.F., and T.A.C. designed the experiments and edited the manuscript.

${ }^{1}$ Corresponding author. E-mail: kencho@ufl.edu.
'Trusty Rusty (TR)' and 'Twist and Twirl (TT)', were selected for this experiment. Fifteen meristem cuttings (5-7 cm in length) with three to four leaves were taken per cultivar from fully grown plants and the fresh weight of each cutting was recorded. The cuttings were immediately put into six-cell packs of black polyethylene trays $(5 \times 3.3 \times$ 2.25 inches) filled with ProMix (Premier Tech Ltd., Quebec Canada) potting soil containing $75 \%$ to $80 \%$ Canadian sphagnum moss. A total of 21 cuttings (seven cultivars, three replications) were placed randomly together inside each illumination chamber. The growth room having illumination chambers was maintained at $25 \pm 1.5^{\circ} \mathrm{C}$ and set up $16 \mathrm{~h}$-photoperiod a day. Irrigation was made as needed by hand (about twice a week).

Twenty-eight days after treatments were initiated, we took pictures to compare L*a*b*/RGB coloration. Three leaf spots were selected randomly from the pictures to determine RGB values using the ImageJ (1.50i) program (http://imagej.nih.gov/ij). The RGB values were converted into the CIELAB (International Commission on Illumination $L^{*} a^{*} b^{*}$ scale) system using color converter software (www.ColorMine.com). The $\mathrm{L}^{*}$ represents the lightness of color from 0 to 100 , being small for dark colors and large for light colors. The $a^{*}$ value is negative for greenish and positive for reddish coloration. The $b^{*}$ value is negative for blue and positive for yellow. Both the $\mathrm{a}^{*}$ and the $\mathrm{b}^{*}$ scales range from -60 to 60 (Dussi et al., 1995). Chroma parameter $\left(C^{*}\right)$ values were calculated with the equation: $\mathrm{C}^{*}=\left(\mathrm{a}^{* 2}+\mathrm{b}^{* 2}\right)^{1 / 2}$, which indicates the vividness of color (Xue et al., 2016).

Afterward, cuttings were collected from the trays and carefully rinsed with running water to remove soil. They were then blotted with paper towels several times and weighed for their final mass measurements. Relative fresh weight ratio was calculated based on the final fresh weight and initial fresh weight of cuttings. The final number of leaves, the longest root length, and total root number of each cutting were counted. Samples were then placed into a dry oven at $75{ }^{\circ} \mathrm{C}$ for $48 \mathrm{~h}$ and weighed for their dry mass. Water content and dry mass percentage were calculated based on the dry and fresh weight. The roots were then cut from the stalks and reweighed for the calculation of top-to-root ratio.

In vitro shoot tip propagation of coleus 'Gator Glory'. Coleus 'Gator Glory' was chosen for in vitro propagation. Fullstrength MS basal salt medium (SigmaAldrich, St. Louis, MO) containing 0.8\% agar and 3\% sucrose was used for all the in vitro experiments. Following the addition of 2-(N-morpholino) ethane sulfonic acid $(0.5$ $\mathrm{g} / \mathrm{L}$ ), the growing media was adjusted to $\mathrm{pH}$ 5.7. Newly emerged shoots $(1-1.5 \mathrm{~cm}$ in length) having two to four leaves were cut carefully and put onto the solidified MS agar medium (11 shoot tips per plate). Three petri dishes were placed in a separate illumination chamber installed with $\mathrm{R}$, B, or $\mathrm{G}$ light individually and three petri dishes under CWF lamp (4100K), widely used light sources for tissue culture facilities for the first experiment. Each chamber was set up with a 16-h photoperiod a day. Leaf and root lengths, leaf width, and root number were measured every $5 \mathrm{~d}$ to examine growth rate during the experimental period ( $20 \mathrm{~d})$. Two mixed lights, $\mathrm{R}+\mathrm{G}(80: 20)$ and $\mathrm{R}+\mathrm{G}+\mathrm{B}$ (40:20:40), were added with three light treatments (W, R, and B) for the second experiment. Shoot tips having two to four leaves were placed onto the MS agar medium aseptically, then the plates were placed under five different light treatments for $28 \mathrm{~d}$. On the final day, the adventitious root number of cuttings and the longest root length were measured.

The ratio of petiole to leaf was calculated based on whole leaf and petiole length measurements. The second internodes from the shoot apex were measured with a digital caliper (Mitutoyo, Kawasaki, Japan), and three newly developed leaves from shoots in each plate were selected randomly for calculating average leaf area using the ImageJ program (1.50i). Each plant was removed carefully from the agar medium and blotted several times using paper towel for the fresh weight measurement. The plants were dried inside an oven at $75{ }^{\circ} \mathrm{C}$ for $48 \mathrm{~h}$ and weighed. Leaf chlorophyll pigment was extracted from $100 \mathrm{mg}$ of fresh leaves at $65{ }^{\circ} \mathrm{C}$ for $30 \mathrm{~min}$ in a $10-\mathrm{mL}$ dimethyl sulfoxide solution (Thermo Fisher Scientific Inc., Hampton, NH). Each absorbance was recorded at 645 and $663 \mathrm{~nm}$ using a spectrophotometer (Bio-Rad, Hercules, CA), and both chlorophyll $\mathrm{a}$ and $\mathrm{b}$ contents were determined with Arnon's equation based on the fresh weight (Hiscox and Israelstam, 1979).

Statistical data analysis. The whole experiment was repeated twice. Each vegetative cutting had three replications per cultivar, and the growth data from each cultivar were separately or collectively compared by one-way or two-way analysis of variance using JMP Pro software (SAS Institute Inc., Cary, NC) to evaluate the effects of light treatments. For the shoot tip cuttings in vitro, three plates were placed under each light treatment chamber and every plate contained six shoots. Mean separations and comparisons were carried out with TukeyKramer honestly significant difference with JMP Pro or Duncan's multiple range tests at $P<0.05$ with XLSTAT software (Addinsoft, Paris, France). Nonparametric statistical analysis was applied to the leaf chroma data using the Kruskal-Wallis test and each mean of rank was compared by chi-square value $\left(\chi^{2} .05, \mathrm{n}=4 ; 9.488\right)$.

\section{Results}

Vegetative cutting propagation in soil for seven coleus cultivars. The root and vegetative growth were evaluated on day 28 after the light treatments were initiated. $\mathrm{R}$ lighttreated cuttings developed the most adventitious roots in six cultivars, whereas $G$ light 

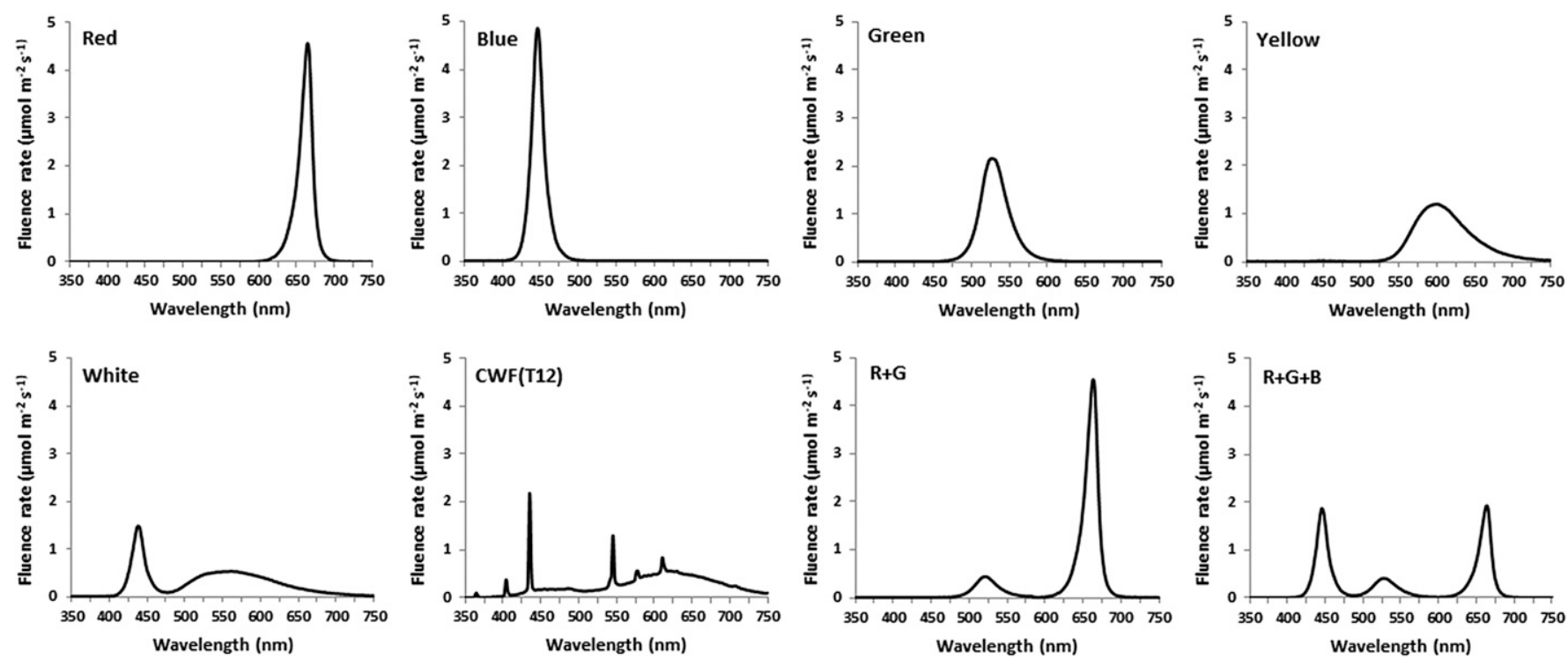

Fig. 1. Spectroradiometer readings of the light qualities used in these studies. All treatments represent the narrow-bandwidth or combined lights generated at a fluence level at $100 \pm 5 \mu \mathrm{mol} \cdot \mathrm{m}^{-2} \cdot \mathrm{s}^{-1}$. $\mathrm{R}+\mathrm{G}=$ mixture of red and green light; $\mathrm{R}+\mathrm{G}+\mathrm{B}=$ mixture of red, green, and blue light.

exposure resulted in less adventitious roots compared with other light treatments in most cultivars (Table 1). 'AR', LT', and 'OS' of R light treatment had significantly more adventitious roots than those of other treatments. The effect of B light on root formation was inconsistent with the cultivars. W or Y light did not increase the root number like $\mathrm{R}$ light. $\mathrm{R}$ light also significantly enhanced the root growth in 'AR' and 'VL', and the longest roots $(13.9,17.8,16.2$, and $15.5 \mathrm{~cm})$ were observed in 'AR', 'LT', 'OS', and 'VL', respectively, under $\mathrm{R}$ light (Table 1). G light did not improve root growth in most cultivars, and the shortest roots were measured in 'AR' (4.9 cm), 'OS' (6.2 cm), 'VL' $(5.1 \mathrm{~cm})$, and 'TR' $(9.5 \mathrm{~cm})$ under $\mathrm{G}$ light treatment (Table 1). B and W light treatment did not show any enhanced effects in root development. There were no significant different root numbers and lengths in 'TT'. Significantly more new leaves ( 7.67 and 10.67 , respectively) were developed in 'LB' and 'OS' when exposed to $\mathrm{R}$ light compared with the cuttings grown under $\mathrm{W}$ and $\mathrm{B}$ light (Table 1). Light treatment did not affect new leaf development in other five cultivars.

Table 2 shows the combined results of the seven cultivars for the fresh and dry mass data measured by light treatment. The cuttings grown under R light gained the greatest fresh weight (3.05 g), and it was significantly more than that $(1.96 \mathrm{~g})$ of $\mathrm{G}$ light. Two-way analysis of variance indicated that the gained fresh weight was also significantly different among the cultivars, but no statistical interactions were found between cultivar and light treatment (Table 2). When the initial and final fresh weight of cuttings were compared, R light treatment significantly increased the fresh weight (5.26-fold), followed by B (4.01-fold) and Y (3.99-fold). The smallest increase of fresh weight was observed (3.22-fold) in $\mathrm{G}$ light treatment (Table 2). It was noticeable that $\mathrm{R}$ light cuttings had significantly more dry mass content $(9.63 \%)$ than those of $\mathrm{W}$ and $\mathrm{G}$ light ( $7.85 \%$ and $5.86 \%$, respectively). R light cuttings also had the greatest shoot dry $(0.29 \mathrm{~g})$ and root dry mass $(0.7 \mathrm{~g})$, which was significantly more than $G$ light cuttings (Table 2). There were no differences in fresh and dry mass between $\mathrm{B}$ light- and $\mathrm{W}$ lighttreated cuttings. The greatest top-to-root ratio (6.83) was observed in cuttings exposed to $G$ light, followed by Y light cuttings (5.84) due to less root number and lower root dry weight than other light treatment (Table 1 and Table 2). Based on the whole measurement of the cuttings by cultivars and light treatments, we figured out a significantly positive correlation $\left(R^{2}=0.598, P<0.001\right)$ between the formation of adventitious roots and gained fresh weight of cuttings $(\Delta \mathrm{FM}$; final fresh weight - initial fresh weight). Another positive correlation $\left(R^{2}=0.385, P<0.0001\right)$ also was detected between adventitious root number and shoot dry mass of coleus cuttings (Fig. 2).

Obvious leaf color transitions were detected in most cultivars on day 28 after cuttings were placed under different light treatment (Table 3). The most remarkable change was found in coleus under $\mathrm{R}$ light exposure, which significantly increased $\mathrm{a}^{*}$ value (more reddish color) in all cultivars except 'LB' (Table 3). The leaves of 'LT' showed a reddish color from the leaf edge after R light treatment. On the contrary, G light exposure caused the leaves of 'AR', 'LB', 'OS', 'TR', and 'TT' significantly more greenish (decreased $\mathrm{a}^{*}$ values) (Table 3 ). Also, when treated with $G$ light, there were significant increases of lightness $\left(\mathrm{L}^{*}\right)$ in leaves of 'AR' and 'LB'. The red sections all but disappeared in 'LB' leaves grown under Y and $\mathrm{G}$ light. The B light made the leaves of most cultivar darker (decreases in $\mathrm{L}^{*}$ value), but not significantly. Significant differences in $b^{*}$ values were detected in the leaves of 'LB',
'VL', and 'TR', where the values were greater under $Y$ and $G$ light compared with $\mathrm{W}, \mathrm{R}$, and $\mathrm{B}$ light treatment (Table 3 ). The $\mathrm{C}^{*}$ were significantly decreased in 'AR', 'TR', and 'TT' under G light, meaning the leaves became less vivid in color than in other light treatments.

In vitro shoot tip propagation of coleus 'Gator Glory'. When the coleus shoot tips were aseptically cultured onto MS agar medium under three LEDs (R, B, and $\mathrm{G}$ ) and CWF lamps $(4100 \mathrm{~K})$, $\mathrm{R}$ light treatment initiated rooting more rapidly than the other lights, as seen by the significantly greater rooting rates $(20 \%$ and $63.6 \%)$ at day 5 and day 10 (Table 4). R light-treated cuttings also had more roots (12.3 per shoot) than other treatments (Fig. 3B). No roots were formed from the shoots under CWF, G, and B light on day 5 (Table 4). Exposed to B light, the cuttings showed the lowest rooting (59.1\%) and the least roots (5.8 per shoot tip) at day 20. G light as well as R light enhanced root growth, whereas roots of the B light treatment did not show normal development, resulting in the shortest roots $(1.1 \mathrm{~cm})$ (Fig. 3A). CWF, $\mathrm{R}$, and $\mathrm{G}$ light leaves kept growing throughout the experiment, but B light-treated leaves did not remain alive, showing browning, and new leaves began to develop after $10 \mathrm{~d}$. Newly emerged leaves were abnormally compact and grew very slowly under B light, resulting in reduced leaf lengths and widths compared with the initial measurements (Fig. 3C). On the contrary, R light increased leaf length by more than double (from $1 \mathrm{~cm}$ to $2.3 \mathrm{~cm}$ ) in $20 \mathrm{~d}$ after being placed onto the MS medium (Fig. 3C and D). The root and shoot growth of $\mathrm{G}$ light treated-shoot tips were better than those of CWF and B light treatments, which demonstrated different results from vegetative cuttings in soil (Table 1). We found $\mathrm{R}$ and $\mathrm{G}$ light showed better shoot and root growth from the study of single light treatments (Fig. 3). Therefore, the 
Table 1. Root number, root length, and new leaf number of seven coleus cultivars propagated in soil under five different light treatments for $28 \mathrm{~d}$.

\begin{tabular}{|c|c|c|c|c|c|c|}
\hline \multirow[b]{2}{*}{ Cultivar } & \multirow[b]{2}{*}{ Parameters } & \multicolumn{5}{|c|}{ Light treatment } \\
\hline & & White $^{z}$ & Yellow & Red & Blue & Green \\
\hline \multirow[t]{3}{*}{ Abbey Road (AR) } & Root number & $8.67 b^{y}$ & $9.00 \mathrm{~b}$ & $14.00 \mathrm{a}$ & $9.67 \mathrm{~b}$ & $5.67 \mathrm{~b}$ \\
\hline & Root length $(\mathrm{cm})$ & $9.67 \mathrm{~b}$ & $9.77 \mathrm{~b}$ & $13.87 \mathrm{a}$ & $9.73 \mathrm{~b}$ & $4.93 \mathrm{~b}$ \\
\hline & New leaf number & $4.00 \mathrm{a}$ & $4.00 \mathrm{a}$ & $3.33 \mathrm{a}$ & $2.67 \mathrm{a}$ & $2.00 \mathrm{a}$ \\
\hline \multirow[t]{3}{*}{ Lime Time (LT) } & Root number & $26.67 \mathrm{~b}$ & $25.33 \mathrm{bc}$ & $34.67 \mathrm{a}$ & $17.33 \mathrm{~d}$ & $20.00 \mathrm{~cd}$ \\
\hline & Root length $(\mathrm{cm})$ & $15.10 \mathrm{ab}$ & $11.33 \mathrm{~b}$ & $17.80 \mathrm{a}$ & $17.57 \mathrm{ab}$ & $16.83 \mathrm{ab}$ \\
\hline & New leaf number & $5.67 \mathrm{a}$ & $4.67 \mathrm{a}$ & $8.33 \mathrm{a}$ & $7.33 \mathrm{a}$ & $7.00 \mathrm{a}$ \\
\hline \multirow[t]{3}{*}{ Limon Blush (LB) } & Root number & $27.33 \mathrm{bc}$ & $37.00 \mathrm{ab}$ & $46.67 \mathrm{ab}$ & $23.00 \mathrm{c}$ & $22.67 \mathrm{c}$ \\
\hline & Root length $(\mathrm{cm})$ & $17.93 \mathrm{a}$ & $11.93 \mathrm{ab}$ & $8.97 \mathrm{~b}$ & $17.07 \mathrm{a}$ & $10.67 \mathrm{ab}$ \\
\hline & New leaf number & $3.33 \mathrm{~b}$ & $5.00 \mathrm{ab}$ & $7.67 \mathrm{a}$ & $3.33 \mathrm{~b}$ & $4.67 \mathrm{ab}$ \\
\hline \multirow[t]{3}{*}{ Oxford Street (OS) } & Root number & $38.67 \mathrm{~b}$ & $35.67 \mathrm{~b}$ & $50.00 \mathrm{a}$ & $38.67 \mathrm{~b}$ & $20.00 \mathrm{c}$ \\
\hline & Root length $(\mathrm{cm})$ & $12.90 \mathrm{ab}$ & $9.33 \mathrm{bc}$ & $16.17 \mathrm{a}$ & $11.83 \mathrm{~b}$ & $6.23 \mathrm{c}$ \\
\hline & New leaf number & $6.67 \mathrm{~b}$ & $5.00 \mathrm{ab}$ & $10.67 \mathrm{a}$ & $7.00 \mathrm{~b}$ & $2.67 \mathrm{~b}$ \\
\hline \multirow[t]{3}{*}{ Velveteen (VL) } & Root number & $33.67 \mathrm{~b}$ & $43.33 \mathrm{ab}$ & $53.00 \mathrm{a}$ & $52.33 \mathrm{ab}$ & $34.33 \mathrm{~b}$ \\
\hline & Root length $(\mathrm{cm})$ & $6.23 \mathrm{c}$ & $6.50 \mathrm{c}$ & $15.47 \mathrm{a}$ & $11.57 \mathrm{~b}$ & $5.13 \mathrm{c}$ \\
\hline & New leaf number & $12.67 \mathrm{a}$ & $19.17 \mathrm{a}$ & $19.67 \mathrm{a}$ & $21.33 \mathrm{a}$ & $10.33 \mathrm{a}$ \\
\hline \multirow[t]{3}{*}{ Trusty Rusty (TR) } & Root number & $35.67 \mathrm{~b}$ & $37.00 \mathrm{~b}$ & $48.33 \mathrm{a}$ & $45.67 \mathrm{a}$ & $21.33 \mathrm{c}$ \\
\hline & Root length $(\mathrm{cm})$ & $12.53 \mathrm{a}$ & $10.10 \mathrm{~b}$ & $14.10 \mathrm{a}$ & $14.10 \mathrm{a}$ & $9.53 \mathrm{~b}$ \\
\hline & New leaf number & $4.33 \mathrm{a}$ & $8.33 \mathrm{a}$ & $9.33 \mathrm{a}$ & $5.33 \mathrm{a}$ & $6.00 \mathrm{a}$ \\
\hline \multirow[t]{3}{*}{ Twist and Twirl (TT) } & Root number & $30.00 \mathrm{a}$ & $36.50 \mathrm{a}$ & $29.00 \mathrm{a}$ & $31.33 \mathrm{a}$ & $23.67 \mathrm{a}$ \\
\hline & Root length (cm) & $15.93 \mathrm{a}$ & $10.95 \mathrm{a}$ & $15.30 \mathrm{a}$ & $17.23 \mathrm{a}$ & $11.70 \mathrm{a}$ \\
\hline & New leaf number & $4.67 \mathrm{a}$ & $4.00 \mathrm{a}$ & $4.33 \mathrm{a}$ & $3.33 \mathrm{a}$ & $4.00 \mathrm{a}$ \\
\hline
\end{tabular}

${ }^{\mathrm{z}}$ White (437.4 nm at peak, $19.4 \mathrm{~nm}$ of FWHM and $559.5 \mathrm{~nm}$ at peak, $126.5 \mathrm{~nm}$ of FWHM), yellow (601.9 nm at peak, $79.5 \mathrm{~nm}$ of FWHM), red (663.4 nm at peak, $18.8 \mathrm{~nm}$ of FWHM), blue (445.7 nm at peak, $18.3 \mathrm{~nm}$ of FWHM), and green (530.0 nm at peak, $40.0 \mathrm{~nm}$ of FWHM).

${ }^{y}$ Mean separation by Duncan's multiple range test (analysis of variance, $\left.P \leq 0.05\right)$. Different letters in a row indicate that means $(\mathrm{n}=6)$ are significantly different. FWHM = full width at half maximum.

Table 2. Quantitative developmental traits for the cuttings of seven coleus cultivars propagated in soil under five different light treatments for $28 \mathrm{~d}$.

\begin{tabular}{|c|c|c|c|c|c|c|c|c|}
\hline \multirow[b]{2}{*}{ Parameters } & \multicolumn{5}{|c|}{ Light treatment } & \multicolumn{3}{|c|}{ Probability $>$ F ratio ${ }^{y}$} \\
\hline & White $^{z}$ & Yellow & Red & Blue & $\overline{\text { Green }}$ & Cultivars & Light & Cultivar*Light \\
\hline Gained fresh weight (g) & $2.29 \mathrm{ab}$ & $2.27 \mathrm{ab}$ & $3.05 \mathrm{a}$ & $2.40 \mathrm{ab}$ & $1.96 \mathrm{~b}$ & $<0.0001^{*}$ & $0.0002 *$ & 0.2637 \\
\hline Gained FW ratio ${ }^{\mathrm{x}}$ & $3.41 \mathrm{~b}$ & $3.99 \mathrm{~b}$ & $5.26 \mathrm{a}$ & $4.01 \mathrm{~b}$ & $3.22 \mathrm{~b}$ & 0.339 & $<0.0001 *$ & 0.0423 \\
\hline Dry mass content ${ }^{\mathrm{w}}$ & $7.85 \mathrm{~b}$ & $7.99 \mathrm{ab}$ & $9.63 \mathrm{a}$ & $8.63 \mathrm{ab}$ & $5.86 \mathrm{c}$ & $<0.0001^{*}$ & $<0.0001^{*}$ & 0.5836 \\
\hline Shoot dry mass (g) & $0.19 \mathrm{~b}$ & $0.20 \mathrm{~b}$ & $0.29 \mathrm{a}$ & $0.21 \mathrm{ab}$ & $0.13 \mathrm{~b}$ & $<0.0001^{*}$ & $<0.0001^{*}$ & 0.6406 \\
\hline Root dry mass (g) & $0.05 \mathrm{ab}$ & $0.04 \mathrm{bc}$ & $0.07 \mathrm{a}$ & $0.05 \mathrm{ab}$ & $0.02 \mathrm{c}$ & $<0.0001^{*}$ & $<0.0001^{*}$ & 0.4900 \\
\hline TR ratio ${ }^{\mathrm{v}}$ & $4.44 \mathrm{bc}$ & $5.84 \mathrm{ab}$ & $4.58 \mathrm{bc}$ & $4.07 \mathrm{c}$ & $6.83 \mathrm{a}$ & $<0.0001^{*}$ & $<0.0001 *$ & $<0.0001^{*}$ \\
\hline
\end{tabular}

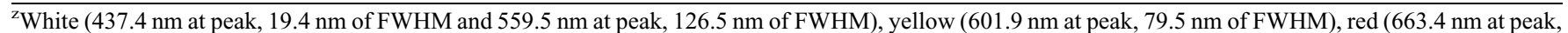
$18.8 \mathrm{~nm}$ of FWHM), blue (445.7 nm at peak, $18.3 \mathrm{~nm}$ of FWHM), green (530.0 nm at peak, $40.0 \mathrm{~nm}$ of FWHM).

${ }^{\mathrm{y}}$ Two-way analysis of variance test was done to evaluate the significance of cultivar or light treatment and their interaction with least square fit. Mean separation and comparison were done with the Tukey-Kramer honestly significant difference test $(P \leq 0.05)$. Different letters in a row indicate that means $(\mathrm{n}=21)$ are significantly different.

${ }^{\mathrm{x}}$ Gained fresh weight ratio $=($ final fresh weight - initial fresh weight $) /$ initial fresh weight.

${ }^{\mathrm{w}}$ Dry mass content $(\%)=$ final dry mass / final fresh weight $\times 100$.

${ }^{\mathrm{v}}$ Top to root ratio $=$ shoot dry mass $/$ root dry mass.

FWHM = full width at half maximum.

*indicates that independent variables or their interaction are statistically significant.

combination of two lights $(\mathrm{R}+\mathrm{G})$ was set up in the next experimental design. The mixed light of $\mathrm{R}+\mathrm{G}+\mathrm{B}$ also was included to elucidate the effect of $\mathrm{B}$ light because the combination was reported to make enhanced vegetative growth in Lactuca sativa (Kim et al., 2004a), even though B light negatively affected on shoot and root growth in the previous experiment.

Cuttings propagated under $\mathrm{R}$ or $\mathrm{R}+\mathrm{G}$ light had significantly more roots ( 14.8 or 11.4 per shoot respectively) than $\mathrm{W}$ or $\mathrm{B}$ light (Table 5). The longest root $(8.04 \mathrm{~cm})$ was observed in the $\mathrm{R}+\mathrm{G}$ light treatment. W light-treated shoots did not attain normal root development in that the average root length was only $2.5 \mathrm{~cm}$ and just 5.4 adventitious roots were formed per cutting (Fig. 4D, Table 5). Interestingly, the exposure to $\mathrm{W}, \mathrm{B}$, or $\mathrm{R}+\mathrm{G}+\mathrm{B}$ lights resulted in rosette-type leaves (Fig. 5), which were significantly smaller and more compact than the leaves formed under $\mathrm{R}$ or $\mathrm{R}+\mathrm{G}$ light treatment (Fig. 4B and C). B light exposure produced the smallest leaves, $65.09 \mathrm{~mm}^{2}$, which was $60 \%$ smaller compared with those $\left(112.9 \mathrm{~mm}^{2}\right.$ ) under $\mathrm{R}+\mathrm{G}$ treatment (Table 5). The addition of $G$ to $R$ light $(R+G)$ significantly increased the leaf, petiole, and internode compared with those under single $\mathrm{R}$ light (Fig. 4). These increases could especially be seen in the petiole with a length of $0.86 \mathrm{~cm}$, occupying $37.7 \%$ of the total leaf length in $\mathrm{R}+\mathrm{G}$ light treatment (Table 5). In contrast, B light appeared to decrease the petiole portion of the total leaf length. When the shoots were exposed to $\mathrm{R}+\mathrm{G}+\mathrm{B}$ or $\mathrm{B}$ light, the petioles were less than $0.5 \mathrm{~cm}$, occupying just $14.74 \%$ or $12.76 \%$ of leaf, respectively (Table 5). The greatest vegetative growth in shoot fresh weight $(279.72 \mathrm{mg}$ ) was observed in $\mathrm{R}+\mathrm{G}$ light treatment and the least (169.44 $\mathrm{mg}$ ) in W light. Significantly more dry mass was measured in $\mathrm{B}$ and $\mathrm{R}+\mathrm{G}$ light than $\mathrm{W}$ light (Table 5). B light exposure significantly increased chlorophyll content in leaves. Both chlorophyll $a$ and $b$ contents were much more in $\mathrm{R}+\mathrm{G}+\mathrm{B}$ and $\mathrm{B}$ light compared with other treatments (Fig. 4). The lowest chlorophyll $a$ and $b$ were observed in the leaves receiving $\mathrm{R}$ light treatment.

\section{Discussion}

Adventitious roots are normally induced by wounding, light, or exogenous auxin application from the cells neighboring vascular tissues, and then once developed, they carry out fundamental functions to absorb water and minerals from soil and to store photo-assimilates (Bellini et al., 2014; Sorin et al., 2005). Therefore, well-developed rooting systems correlate positively with plant growth (Howard, 1996), and our results demonstrated that coleus cuttings having more roots gained significantly more shoot dry mass during cutting propagation periods (Fig. 2). Auxin plays a pivotal role in adventitious root formation, and endogenous auxin 

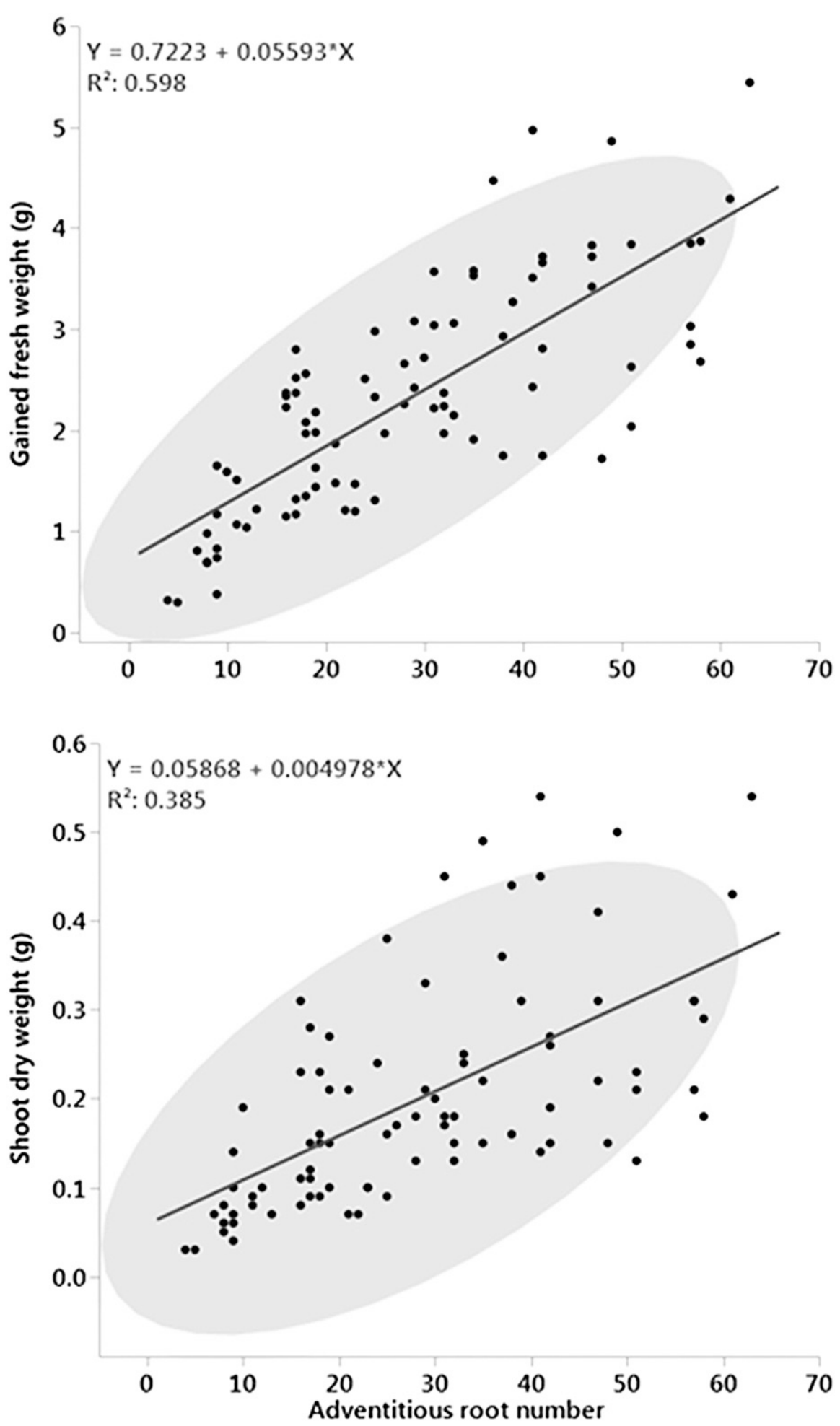

Fig. 2. Linear regression showed a significant positive correlation between adventitious root number and the gained fresh weight $(\Delta \mathrm{FW}=$ final $\mathrm{FW}$ - initial $\mathrm{FW})$ of coleus (Plectranthus scutellarioides) vegetative cuttings in soil for $28 \mathrm{~d}\left(R^{2}=0.598^{*}, P<0.0001\right)$ (upper panel). Another positive correlation was observed between adventitious root number and shoot dry mass $\left(R^{2}=0.385^{*}, P<0.0001\right)$ (lower panel). The eclipse covers $90 \%$ of whole data calculated from JMP Pro software.

homeostasis, transport, and signaling were controlled in a light-dependent manner in Arabidopsis (Pacurar et al., 2014; Sorin et al., 2005). Red light was reported to enhance rooting of Jatropha curcas, allowing $80 \%$ survival rate after acclimatization (Daud et al., 2013) and improve lateral root formation rate up to $67 \%$ in Protea cynaroides from $7 \%$ of white fluorescent light due to reduced endogenous 3,4-dihydroxybenzoic acid and ferulic acid (Wu and Lin, 2012). Low intensity of red light $\left(45 \mu \mathrm{mol} \cdot \mathrm{m}^{-2} \cdot \mathrm{s}^{-1}\right)$ also signifi- cantly increased root number and shoot weight in strawberry propagated in vitro (Nhut et al., 2003).

In our studies, $\mathrm{R}$ light exposure noticeably increased cutting biomass (fresh and dry mass) of five coleus cultivars compared with W light, likely due to enhanced adventitious root development (Table 1). Longer roots and bigger leaves also were observed in coleus shoots in vitro cultures under $\mathrm{R}$ light treatment compared with W light (Fig. 3). Poudel et al. (2008) observed longer shoots and greater rooting percentage for two grape cultivars propagated in vitro under red light and suggested direct relationship between plant height and rooting percentage. In coleus, $\mathrm{R}$ light seemed to enhance root initiation from shoot tips more quickly than other light treatments (Table 4). When we tested W light treatment for both cuttings in soil and in vitro experiments that included two peaks in the blue and yellow area $(450 \mathrm{~nm}$ and $580 \mathrm{~nm})$ (Fig. 1), the unsatisfactory root development considerably could be related with very weak $\mathrm{R}$ light wavelength $(660-680 \mathrm{~nm})$. R light conclusively should be required for root initiation and growth for the cutting propagation based on our experiments and other related studies.

Our experiments demonstrated that $\mathrm{R}$ light exposure significantly increased $\mathrm{a}^{*}$ value (more reddish color) of the leaves in six coleus cultivars during the propagation period (Table 3 ). In coleus, reddish foliage color generally is governed by anthocyanin accumulation in epidermal cells derived from the flavonoid biosynthetic pathway (Mol et al., 1998). Light intensity was reported to be strongly associated with anthocyanin accumulation in coleus leaves based on the involvement of high expression of energy status indicator genes, Lchb2 (light harvesting complex b2) and CBS (Cystathionine$\beta$-synthase) (Nguyen and Dal Cin, 2009). However, our experiments were carried out under relatively low light intensity (100 $\left.\mu \mathrm{mol} \cdot \mathrm{m}^{-2} \cdot \mathrm{s}^{-1}\right)$ in separate chambers. Anthocyanin biosynthesis as phytochemical response was alternatively controlled by an action spectrum ranged from 640 to 670 $\mathrm{nm}$. Under continuous red light, activated PHY B leads to the degradation of phytochrome-interacting factors PIF4 and PIF5, resulting in an increase of anthocyanin biosynthesis in Arabidopsis (Liu et al., 2015). There was a tendency of increased anthocyanin production in red pear (Pyrus L. 'Sensation Red Bartlett'), with longer wavelengths, especially above $600 \mathrm{~nm}$ (Dussi et al., 1995), and more anthocyanin content in cranberry fruits (Vaccinium macrocarpon) as well as enhanced root formation in response to red light (Zhou and Singh, 2002). Therefore, such color transition of coleus leaves exposed to $\mathrm{R}$ light could be possibly explained not by high light intensity but by phytochrome-mediated phytochemical reaction in the present studies.

In response to $B$ or $R+G+B$ light, significantly greater amounts of chlorophyll $a$ and $b$ were extracted from the leaves of coleus 
Table 3. Leaf color transition of vegetative cuttings from seven cultivars of coleus (Plectranthus scutellarioides) grown in soil under five different light treatments for $28 \mathrm{~d}$.

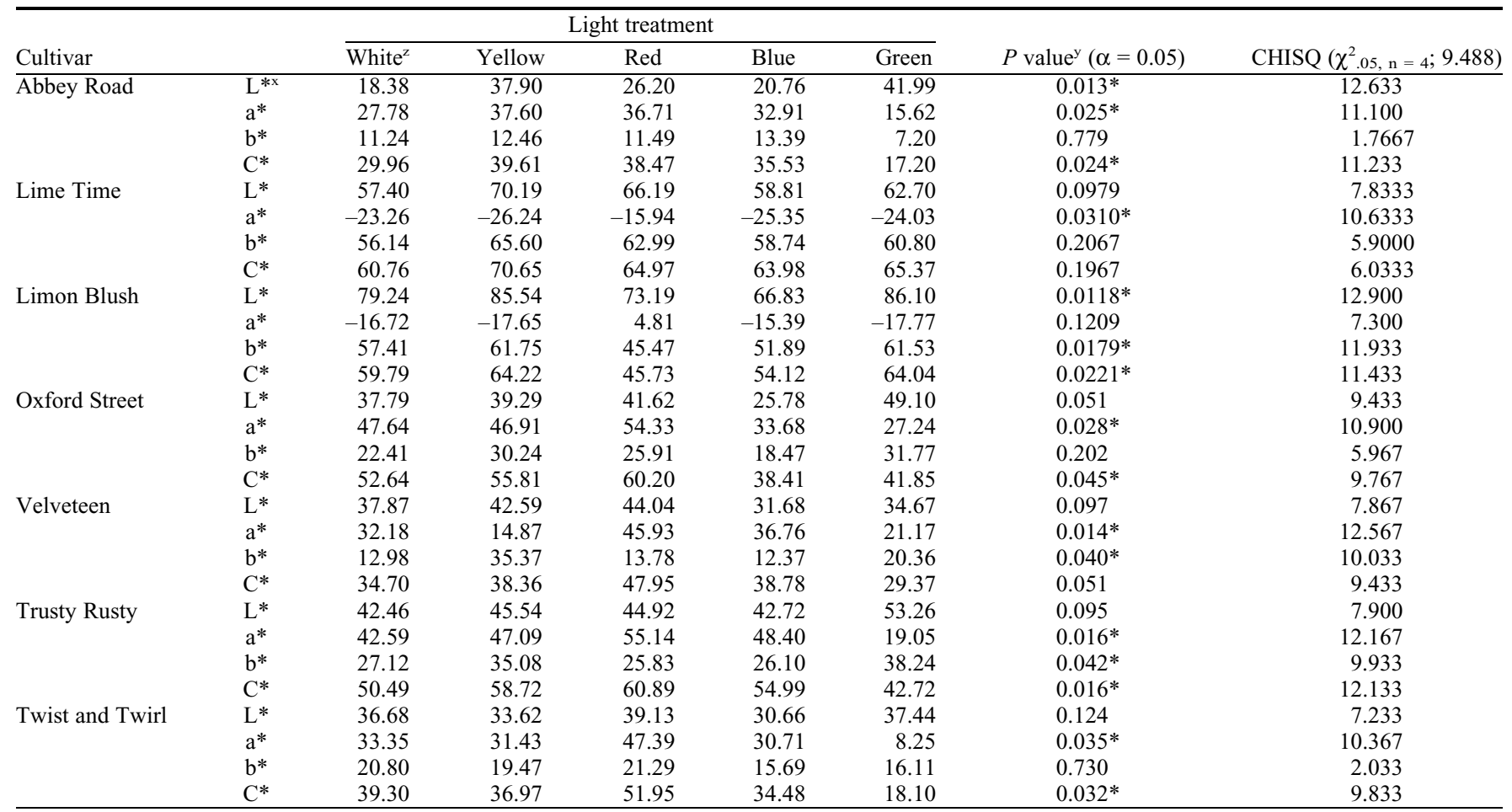

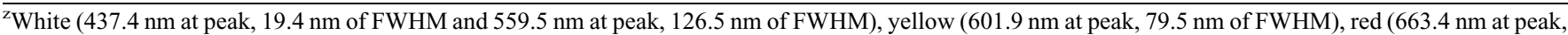
$18.8 \mathrm{~nm}$ of FWHM), blue (445.7 nm at peak, $18.3 \mathrm{~nm}$ of FWHM), green (530.0 nm at peak, $40.0 \mathrm{~nm}$ of FWHM).

${ }^{y}$ Nonparametric statistical analysis (Wilcoxon score rank sums) was performed, and $P$ value and $\chi^{2}$ were calculated with the Kruskal-Wallis test.

${ }^{\mathrm{x}} \mathrm{L}^{*}=$ lightness; $\mathrm{a}^{*}$ and $\mathrm{b}^{*}=$ chromatic components; $\mathrm{C}^{*}=$ chroma.

$\mathrm{CHISQ}=$ chi-squared test; FWHM = full width at half maximum.

Table 4. Root formation rate of coleus (Plectranthus scutellarioides) 'Gator Glory’ propagated from shoot tips onto MS agar medium under different wavelengths of light.

\begin{tabular}{lccc}
\hline & \multicolumn{3}{c}{ Root formation rate (\%) of in vitro cuttings } \\
\cline { 2 - 4 } Light treatment & $5 \mathrm{~d}$ & $10 \mathrm{~d}$ & $15 \mathrm{~d}$ \\
\hline CWF $(\mathrm{T} 12)^{\mathrm{z}}$ & $0.0 \mathrm{~b}^{\mathrm{y}}$ & $18.2 \mathrm{c}$ & $72.7 \mathrm{~b}$ \\
Red $^{\mathrm{x}}$ & $20.0 \mathrm{a}$ & $63.6 \mathrm{a}$ & $90.9 \mathrm{a}$ \\
Blue & $0.0 \mathrm{~b}$ & $27.2 \mathrm{c}$ & $51.8 \mathrm{ab}$ \\
Green & $0.0 \mathrm{~b}$ & $50.0 \mathrm{ab}$ & $90.9 \mathrm{a}$ \\
\hline
\end{tabular}

${ }^{\mathrm{z}}$ Cool-white fluorescence lamp $(40 \mathrm{~W}, \mathrm{~T} 12,4100 \mathrm{~K})$ used conventionally in tissue culture room

${ }^{\mathrm{y}}$ Different letters in a column indicate that means $(\mathrm{n}=9)$ are significantly different $(P \leq 0.05$, Tukey honestly significant difference test).

${ }^{\mathrm{x}}$ Narrow-bandwidth light treatment; red (663.4 nm at peak, $18.8 \mathrm{~nm}$ of FWHM), blue ( $445.7 \mathrm{~nm}$ at peak, $18.3 \mathrm{~nm}$ of FWHM), green $(530.0 \mathrm{~nm}$ at peak, $40.0 \mathrm{~nm}$ of FWHM).

FWHM $=$ full width at half maximum.

shoots grown in vitro (Fig. 4). Similarly, the chlorophyll content decreased under red and increased under blue light in cotton plantlets (Li et al., 2010) and in grape cultured in vitro (Poudel et al., 2008). Chlorophyll is the major photosynthetic pigment synthesized mainly through the tetrapyrrole biosynthesis from glutamate in plastid. Light is vitally required for chlorophyll biosynthesis, and its concentration and composition directly affect the photosynthetic rate of the leaves (Fan et al., 2013b). Blue light reportedly improved 5aminolevulinic acid synthesis in tobacco callus cells (Kamiya et al., 1983) and Chinese cabbage (Fan et al., 2013a), which is the key precursor in the chlorophyll biosynthetic pathway, followed by the conversion into protoporphyrin IX. Li et al. (2017) reported blue light increased the expression of the genes encoding the heme-binding 2-like protein and chloroplast early light-induced protein, which may increase chlorophyll accumulation and promote chloroplast development in grape in vitro propagation. Once exposed to narrow-bandwidth B light, decreased $\mathrm{L}^{*}$ values were detected in the coleus leaves, although they were not significant (Table 3), and similar results were reported that the wavelength from 400 to $500 \mathrm{~nm}$ produced darker, less chromatic pear fruits (Dussi et al., 1995). Blue light has been known to induce chloroplast rearrangement to a "light avoidance" position in the cells, which reduces photochemical efficiency (Arena et al., 2016). B light exposure elicited dark, chlorophyll-rich leaves from coleus shoot tips in vitro supposedly due to enhanced chlorophyll biosynthesis and inefficient photosynthesis (Fig. 4A).

When coleus cuttings and shoot tips received B light treatment, they showed a compact growth, which was a very distinct morphological change. In Arabidopsis, blue light was shown to inhibit hypocotyl elongation by phototropin 1 (phot1) mediating changes in calcium influx into the cytosol (Folta et al., 2003a). Blue light has been reported to inhibit auxin and gibberellin synthesis by activation of a blue light receptor, cryptochrome 1, in Arabidopsis (Folta et al., 2003b; Huché-Thélier et al., 2016). Moni et al. (2015) reported that another B light receptor, phototropin 1, may play negative roles in lateral root elongation and development in Arabidopsis seedlings through auxin-related signal regulation. In wheat, red light made the wheat height higher than other mixed light treatments, but seedling growth was suppressed when blue light was added (Dong et al., 2014). Exposed to blue light for 4 weeks, strawberry shoots showed shorter root lengths, smaller number of roots, and lower dry weight than those 

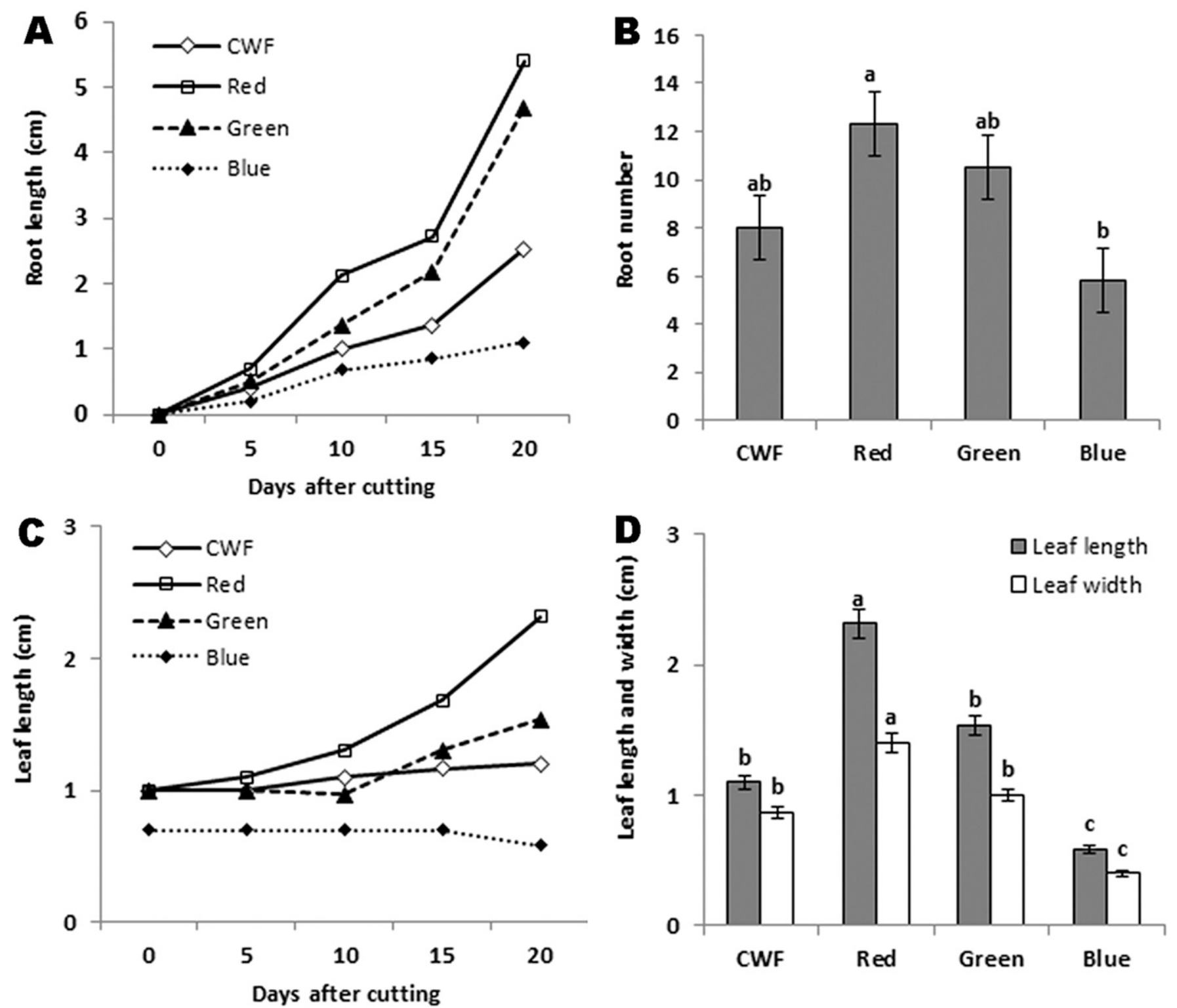

Fig. 3. Root and leaf growth of coleus (Plectranthus scutellarioides) 'Gator Glory' propagated from shoot tip onto Murashige and Skoog agar medium when exposed to different wavelengths of light for $20 \mathrm{~d}$. CWF (cool white fluorescence lamp), red (663.4 nm at peak, $18.8 \mathrm{~nm}$ of FWHM), blue (445.7 nm at peak, $18.3 \mathrm{~nm}$ of FWHM), and green ( $530.0 \mathrm{~nm}$ at peak, $40.0 \mathrm{~nm}$ of FWHM). Root lengths were measured every $5 \mathrm{~d}$. The longest adventitious roots were selected in each plate (A). The numbers of adventitious roots were counted on the day $20(\mathbf{B})$. The leaf length was measured every $5 \mathrm{~d}(\mathbf{C})$. Leaf length and width were measured on the day 20 (D). Mean separation by Duncan's multiple range test (analysis of variance, $P \leq 0.05$ ). Different letters on bars indicate that means $(\mathrm{n}=9)$ are significantly different. Error bars show SE of each light treatment. FWHM = full width at half maximum.

Table 5. Root and leaf growth parameters of coleus (Plectranthus scutellarioides) 'Gator Glory' propagated from shoot tips onto MS agar medium under single or combined wavelengths for $28 \mathrm{~d}$.

\begin{tabular}{|c|c|c|c|c|c|}
\hline \multirow[b]{2}{*}{ Parameters } & \multicolumn{5}{|c|}{ Light treatment } \\
\hline & White $^{z}$ & Red & $\mathrm{R}+\mathrm{G}$ & $\mathrm{R}+\mathrm{G}+\mathrm{B}$ & Blue \\
\hline Root number & $5.40 \mathrm{c}^{\mathrm{y}}$ & $14.80 \mathrm{a}$ & $11.40 \mathrm{ab}$ & $8.40 \mathrm{bc}$ & $7.80 \mathrm{c}$ \\
\hline Fresh weight (mg) & $169.44 \mathrm{~b}$ & $216.32 \mathrm{a}$ & $279.72 \mathrm{a}$ & $226.96 \mathrm{a}$ & $230.86 \mathrm{a}$ \\
\hline Leaf area $\left(\mathrm{mm}^{2}\right)$ & $83.71 \mathrm{ab}$ & $106.25 \mathrm{ab}$ & $112.90 \mathrm{a}$ & $83.82 \mathrm{ab}$ & $65.09 \mathrm{~b}$ \\
\hline Petiole/total leaf length $(\%)^{\mathrm{x}}$ & $19.28 \mathrm{c}$ & $30.20 \mathrm{~b}$ & $37.72 \mathrm{a}$ & $14.74 \mathrm{c}$ & $12.76 \mathrm{c}$ \\
\hline
\end{tabular}

${ }^{\mathrm{z}}$ White (437.4 nm at peak, $19.4 \mathrm{~nm}$ of FWHM and $559.5 \mathrm{~nm}$ at peak, $126.5 \mathrm{~nm}$ of FWHM), red (663.4 nm at peak, $18.8 \mathrm{~nm}$ of FWHM), blue (445.7 nm at peak, $18.3 \mathrm{~nm}$ of FWHM), R+G (red + green, $663.4 \mathrm{~nm}$ at peak, $18.8 \mathrm{~nm}$ of FWHM and $530.0 \mathrm{~nm}$ at peak, $40.0 \mathrm{~nm}$ of FWHM), R+G+B (red + green + blue, $663.4 \mathrm{~nm}$ at peak, $18.8 \mathrm{~nm}$ of FWHM, $530.0 \mathrm{~nm}$ at peak, $40.0 \mathrm{~nm}$ of FWHM, and $445.7 \mathrm{~nm}$ at peak, $18.3 \mathrm{~nm}$ of FWHM).

${ }^{\mathrm{y}}$ Different letters in a column indicate that means $(\mathrm{n}=9)$ are significantly different $(P \leq 0.05$, Tukey honestly significant difference test $)$.

${ }^{x}$ Percentage of petiole length as a part of total leaf length.

FWHM = full width at half maximum.

grown under red or mixed light (Nhut et al., 2003). Our findings coincide with those results in that B light exposure inhibited ad- ventitious root formation and shoot growth of coleus in vitro culture (Fig. 3). Also, light treatments including $450 \mathrm{~nm}$ wavelength
$(\mathrm{W}, \mathrm{B}$, and $\mathrm{R}+\mathrm{G}+\mathrm{B})$ produced significantly shorter internodes from in vitro culture than other light treatments (Fig. 4C), and Li et al. 

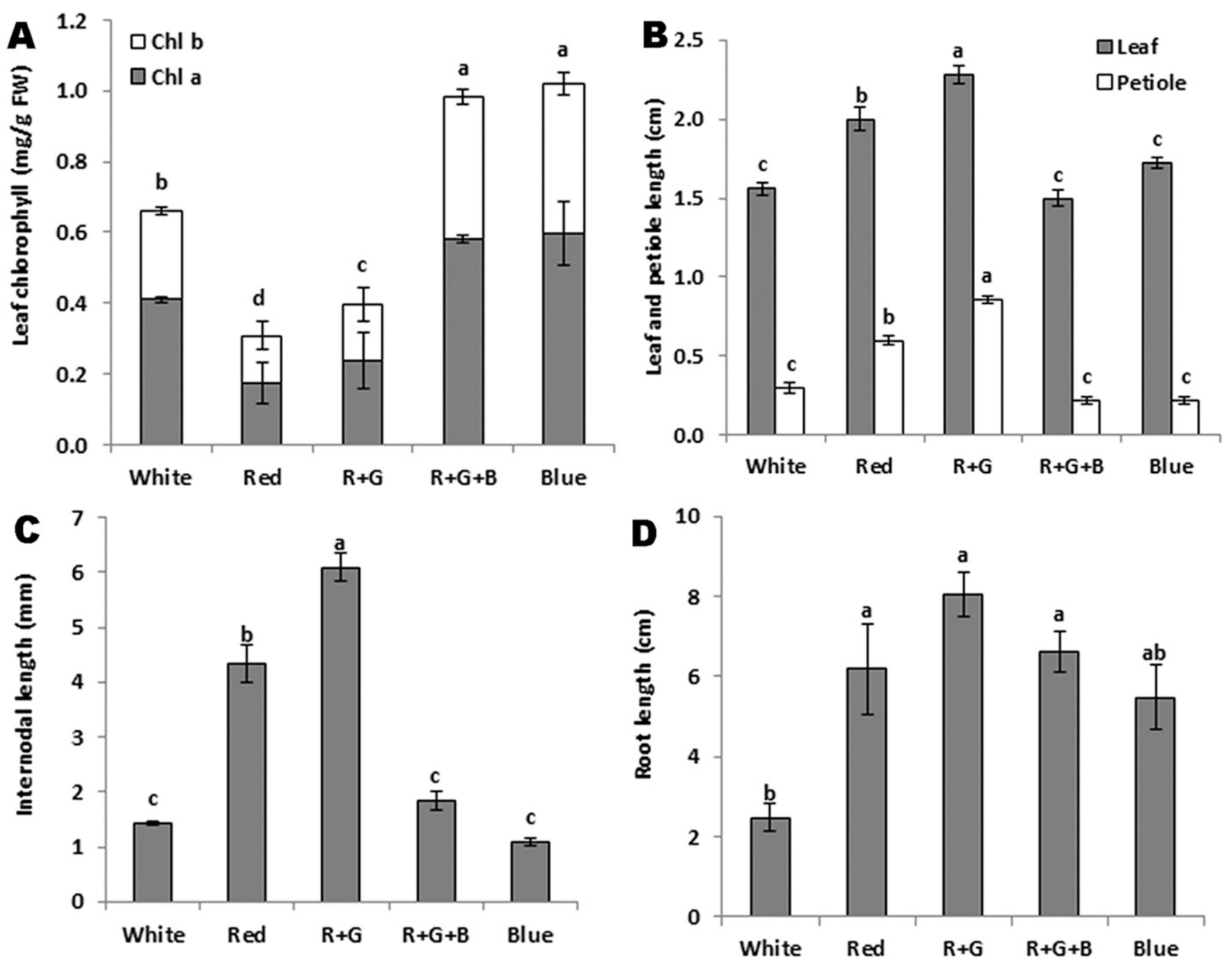

Fig. 4. Featured growth parameters of coleus (Plectranthus scutellarioides) 'Gator Glory' propagated from shoot tip culture under different wavelengths of light and its mixtures for $28 \mathrm{~d}$. White ( $437.4 \mathrm{~nm}$ at peak, $19.4 \mathrm{~nm}$ of FWHM and $559.5 \mathrm{~nm}$ at peak, $126.5 \mathrm{~nm}$ of FWHM), red ( $663.4 \mathrm{~nm}$ at peak, $18.8 \mathrm{~nm}$ of FWHM), blue ( $445.7 \mathrm{~nm}$ at peak, $18.3 \mathrm{~nm}$ of FWHM), R+G (red + green, $663.4 \mathrm{~nm}$ at peak, $18.8 \mathrm{~nm}$ of FWHM and $530.0 \mathrm{~nm}$ at peak, $40.0 \mathrm{~nm}$ of FWHM), and R+G+B (red + green + blue, $663.4 \mathrm{~nm}$ at peak, $18.8 \mathrm{~nm}$ of FWHM, $530.0 \mathrm{~nm}$ at peak, $40.0 \mathrm{~nm}$ of FWHM, and $445.7 \mathrm{~nm}$ at peak, $18.3 \mathrm{~nm}$ of FWHM). Chlorophyll $a$ and $b$ were calculated from absorbance at 645 or $663 \mathrm{~nm}(\mathbf{A})$. Newly developed leaves were selected in each plate. Total length and petiole length were measured separately $(\mathbf{B})$. The second nodes from the bottom of each shoot were measured $(\mathbf{C})$. The three longest roots were measured in each plate $(\mathbf{D})$. Mean separation by Duncan's multiple range test (analysis of variance, $P \leq 0.05)$. Different letters on bars indicate that means $(\mathrm{n}=9)$ are significantly different. Error bars show SE of each light treatment. FWHM = full width at half maximum.

(2010) reported similar results with cotton leaf tissue culture. Plant height and root growth were reduced in response to the blue light treatment in grape in vitro culture, possibly due to the blue light-induced down-regulation in the expression of the auxin-repressed protein gene, which made the endogenous auxin exceed the optimal level ( $\mathrm{Li}$ et al., 2017). The compactness of seedlings could be a desirable characteristic so blue light treatment would be benefit for some specific plant production methods (Wollaeger and Runkle, 2014).

In terms of $\mathrm{G}$ light effects on cutting propagation, there was a discrepancy between the growth of vegetative cuttings in soil and in vitro shoot tip culture. When the vegetative cuttings were exposed to $G$ light, reduced root development (less roots and shorter root lengths) was clearly recognized from the five cultivars (Table 1). The least dry mass content $(5.86 \%)$ demonstrated that the single $\mathrm{G}$ light is an unfavorable condition for cutting propagation in soil (Table 2). When treated with $G$ light, the coleus leaf color became more green (decreased $\mathrm{a}^{*}$ ) and showed lower $C^{*}$ in most cultivars meaning not vivid colors (Table 3 ). On the contrary, there was not a significant difference in the root number per shoot between $\mathrm{R}$ and $\mathrm{G}$ light treatment of in vitro propagation (Fig. 3). Green light (500-550 nm) is known to be either mostly reflected by leaves or penetrate through plant canopies (Folta and Maruhnich, 2007), but the amount of refraction and penetration seems to depend on the plant species (Inada 1976). Even though it is thought not to be absorbed directly by leaves under plant canopies, the green wavelengths may be diffused (detour effect) in the spongy tissue (Terashima et al., 2009) and reflected inside complex network of photosynthetic cells (Kim et al., 2004a). Thus, the typical values of absorbance at $550 \mathrm{~nm}$ range from $50 \%$ in lettuce to $90 \%$ in evergreen broad-leaved trees (Inada, 1976). Plants are reported to have sensitive green light sensors, the phytochromes and cryptochromes, but their efficiency in processing the green light signal is very poor relatively compared with red and blue light, and green light could be functionally similar to far-red light, which informs the plants of unfavorable light conditions (Folta and Maruhnich, 2007).

Like coleus cuttings in soil, leaf lettuce grown under green fluorescent lamps (150 $\mu \mathrm{mol} \cdot \mathrm{m}^{-2} \cdot \mathrm{s}^{-1}$ ) showed the least biomass (leaf area, fresh weight, and dry mass) of all treatments (Kim et al., 2004b). However, Johkan et al. (2012) attempted to strengthen green light intensity up to $500 \mu \mathrm{mol} \cdot \mathrm{m}^{-2} \cdot \mathrm{s}^{-1}$ and obtained drastically improved growth and promoted anthocyanin expression in red lettuce even under single green wavelength (500-599 nm). Our experiments were conducted under relatively low light intensity 


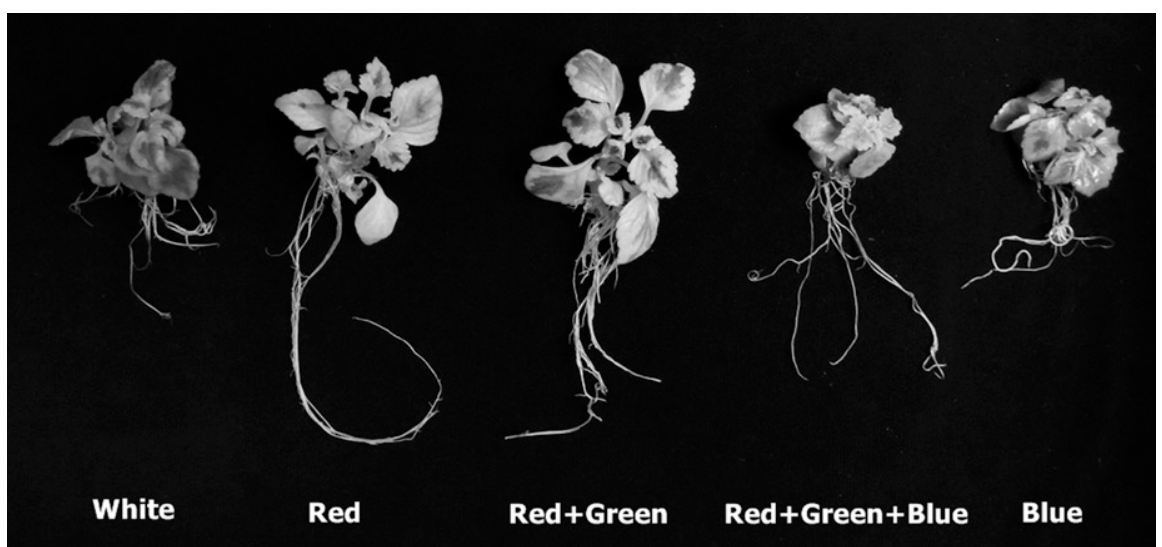

Fig. 5. Coleus (Plectranthus scutellarioides) 'Gator Glory' propagated from shoot tip culture onto Murashige and Skoog agar medium under different wavelengths of light or its mixtures for $28 \mathrm{~d}$. White (437.4 nm at peak, $19.4 \mathrm{~nm}$ of FWHM and $559.5 \mathrm{~nm}$ at peak, $126.5 \mathrm{~nm}$ of FWHM), red (663.4 nm at peak, $18.8 \mathrm{~nm}$ of FWHM), blue ( $445.7 \mathrm{~nm}$ at peak, $18.3 \mathrm{~nm}$ of FWHM), red + green ( $663.4 \mathrm{~nm}$ at peak, $18.8 \mathrm{~nm}$ of FWHM and $530.0 \mathrm{~nm}$ at peak, $40.0 \mathrm{~nm}$ of FWHM), and red + green + blue (663.4 nm at peak, $18.8 \mathrm{~nm}$ of FWHM, $530.0 \mathrm{~nm}$ at peak, $40.0 \mathrm{~nm}$ of FWHM, and $445.7 \mathrm{~nm}$ at peak, $18.3 \mathrm{~nm}$ of FWHM). FWHM = full width at half maximum.

$\left(100 \mu \mathrm{mol} \cdot \mathrm{m}^{-2} \cdot \mathrm{s}^{-1}\right)$, and additional studies will be required with various green light intensity regimes. When the $\mathrm{G}$ light was supplemented with R light, the coleus cuttings showed great increases in the internode (40\% longer than single $\mathrm{R}$ light) and petiole lengths (25\% longer than single $\mathrm{R}$ light). Supplementation of green light $(24 \%)$ to $\mathrm{R}+\mathrm{B}$ light was reported to enhance lettuce growth compared with traditional CWF lamps (Kim et al., 2004a). Thus, the use of green light appears to be beneficial at least for some crops solely or collaboratively with other lights to obtain desirable growth. In Arabidopsis, the petiole increased up to $40 \%$ of the whole leaf length when green light was added to $\mathrm{R}+\mathrm{B}$ light, which is known to be "shade avoidance symptoms" as a morphological adaptation to low light environment under canopy (Wang et al., 2015; Zhang et al., 2011). Terashima et al. (2009) reported that under strong white light, any additional green light absorbed by the lower chloroplasts would increase leaf photosynthesis to a great extent in sunflower. When $G$ light was combined with the $\mathrm{R}$ light in coleus, there were significant increases in root lengths, leaf and petiole lengths, dry mass, and intermodal lengths compared with single $\mathrm{R}$ light treatment (Table 5, Fig. 4). These results indicate the combination of $\mathrm{R}$ and $\mathrm{G}$ light could be a good light source to proliferate coleus shoot tips in vitro.

In the present studies, we demonstrated that various light quality using LEDs caused distinct root development and growth of coleus cuttings, providing some ideas that the production of rooted cuttings could be desirably managed by manipulating wavelengths of light. As described herein, $\mathrm{R}$ light obviously improved and quickened the root formation of coleus cuttings both in soil and in vitro, which may shorten the propagation periods, produce healthy cuttings, and reduce the use of rooting hormone in commercial nurseries. Yield, quality, and costs are vital criteria in agricultural production. Therefore,
CWF, conventionally used in tissue culture, can be replaced with the mixtures of $R, G$, and $\mathrm{B}$ LEDs to maximize energy efficiency and increase product quality. These experiments evaluating the effects of LED lighting are necessary to predict the large-scale applicability in in vitro propagation (Batista et al., 2018). Further research should be performed to optimize the light fluent rate and the mixture ratio of R, G, and B lights for high-quality production of rooted cuttings.

\section{Literature Cited}

Ahkami, A.H., M. Melzer, M.R. Ghaffari, S Pollmann, M.G. Javid, F. Shahinnia, M.R Hajirezaei, and U. Druege. 2013. Distribution of indole-3-acetic acid in Petunia hybrida shoot tip cuttings and relationship between auxin transport, carbohydrate metabolism and adventitious root formation. Planta 238:499517.

Arena, C., T. Tsonev, D. Doneva, V. De Micco, M Michelozzi, C. Brunetti, M. Centritto, S. Fineschi, V. Velikova, and F. Loreto. 2016. The effect of light quality on growth, photosynthesis, leaf anatomy and volatile isoprenoids of a monoterpene-emitting herbaceous species (Solanum lycopersicum $\mathrm{L}$.) and an isoprene-emitting tree (Platanus orientalis L.). Environ. Expt. Bot. 130:122-132.

Batista, D.S., S.H.S. Felipe, T.D. Silva, K.M de Castro, T.C. Mamedes-Rodrigues, N.A Miranda, A.M. Ríos-Ríos, D.V. Faria, E.A Fortini, K. Chagas, and G. Torres-Silva. 2018. Light quality in plant tissue culture: Does it matter? In Vitro Cell. Dev. Biol. Plant 54:195215.

Bellini, C., D.I. Pacurar, and I. Perrone. 2014 Adventitious roots and lateral roots: Similarities and differences. Annu. Rev. Plant Biol 65:639-666.

Christiaens, A., B. Gobin, and M.C. Van Labeke 2016. Light quality and adventitious rooting: A mini-review. Acta Hort. 1134:385-394.

Christiaens, A., M.C. Van Labeke, B. Gobin, and J. Van Huylenbroeck. 2015. Rooting of ornamental cuttings affected by spectral light quality. Acta Hort. 1104:219-224.

Daud, N., A. Faizal, and D. Geelen. 2013. Adventitious rooting of Jatropha curcas L. is stimu- lated by phloroglucinol and by red LED light. In Vitro Cell. Dev. Biol. Plant 49(2):183-190.

Dong, C., Y. Fu, G. Liu, and H. Liu. 2014. Growth, photosynthetic characteristics, antioxidant capacity and biomass yield and quality of wheat (Triticum aestivum L.) exposed to LED light sources with different spectra combinations. J. Agron. Crop Sci. 200(3):219-230.

Dussi, M.C., D. Sugar, and R.E. Wrolstad. 1995 Characterizing and quantifying anthocyanins in red pears and the effect of light quality on fruit color. J. Amer. Soc. Hort. Sci. 120:785-789.

Fan, X., J. Zang, Z. Xu, S. Guo, X. Jiao, X. Liu, and Y. Gao. 2013a. Effects of different light quality on growth, chlorophyll concentration and chlorophyll biosynthesis precursors of non-heading Chinese cabbage (Brassica campestris L.) Acta Physiol. Plant. 35(9):2721-2726.

Fan, X.X., Z.G. Xu, X.Y. Liu, C.M. Tang, L.W. Wang, and X.L. Han. 2013b. Effects of light intensity on the growth and leaf development of young tomato plants grown under a combination of red and blue light. Scientia Hort. 153:50-55.

Folta, K.M., E.J. Lieg, T. Durham, and E.P. Spalding. 2003a. Primary inhibition of hypocotyl growth and phototropism depend differently on phototropin-mediated increases in cytoplasmic calcium induced by blue light. Plant Physiol. 133(4):1464-1470.

Folta, K.M., M.A. Pontin, G. Karlin-Neumann, R. Bottini, and E.P. Spalding. 2003b. Genomic and physiological studies of early cryptochrome 1 action demonstrate roles for auxin and gibberellin in the control of hypocotyl growth by blue light. Plant J. 36(2):203-214.

Folta, K.M. and S.A. Maruhnich. 2007. Green light: A signal to slow down or stop. J. Expt. Bot. 58(12):3099-3111

Gabryszewska, E. and R.M. Rudnicki. 1994. The effects of light quality on the growth and development of shoots and roots of Ficus benjamina in vitro. In III International Symposium on Artificial Lighting in Horticulture. 418:163-168.

Gautam, P., M.T. Terfa, J.E. Olsen, and S. Torre. 2015. Red and blue light effects on morphology and flowering of Petunia x hybrid. Scientia Hort. 184:171-178.

Hiscox, J.D. and G.F. Israelstam. 1979. A method for the extraction of chlorophyll from leaf tissue without maceration. Can. J. Bot 57:1332-1334.

Howard, Y.H. 1996. Relationships between shoot growth and rooting of cuttings in three contrasting species of ornamental shrub. J. Hort. Sci. 71(4):591-605.

Huché-Thélier, L., L. Crespel, J. Le Gourrierec, P. Morel, S. Sakr, and N. Leduc. 2016. Light signaling and plant responses to blue and UV radiations - Perspectives for applications in horticulture. Environ. Expt. Bot. 121:22-38.

Inada, K. 1976. Action spectra for photosynthesis in higher plants. Plant Cell Physiol. 17(2):355365 .

Johkan, M., K. Shoji, F. Goto, S.N. Hahida, and T. Yoshihara. 2012. Effect of green light wavelength and intensity on photomorphogenesis and photosynthesis in Lactuca sativa. Environ. Expt. Bot. 75:128-133.

Kamiya, A., I. Ikegami, and E. Hase. 1983 Effects of light on chlorophyll formation in cultured tobacco cells II. Blue light effect on 5 -aminolevulinic acid formation. Plant Cell Physiol. 24(5):799-809.

Kim, H.H., G.D. Goins, R.M. Wheeler, and J.C. Sager. 2004a. Green-light supplementation for enhanced lettuce growth under red-and 
blue-light-emitting diodes. HortScience 39:16171622.

Kim, H.H., G.D. Goins, R.M. Wheeler, and J.C. Sager. 2004b. Stomatal conductance of lettuce grown under or exposed to different light qualities. Ann. Bot. (Lond.) 94(5):691-697.

Li, C.X., Z.G. Xu, R.Q. Dong, S.X. Chang, L.Z. Wang, M. Khalil-Ur-Rehman, and J.M. Tao. 2017. An RNA-seq analysis of grape plantlets grown in vitro reveals different responses to blue, green, red LED light, and white fluorescent light. Front. Plant Sci. 8:78.

Li, H., Z. Xu, and C. Tang. 2010. Effect of lightemitting diodes on growth and morphogenesis of upland cotton (Gossypium hirsutum L.) plantlets in vitro. Plant Cell Tissue Organ Cult. 103(2):155-163.

Lim, Y.J. and S.H. Eom. 2013. Effects of different light types on root formation of Ocimum basilicum L. cuttings. Scientia Hort. 164:552555.

Liu, Z., Y. Zhang, J. Wang, P. Li, C. Zhao, Y. Chen, and Y. Bi. 2015. Phytochromeinteracting factors PIF4 and PIF5 negatively regulate anthocyanin biosynthesis under red light in Arabidopsis seedlings. Plant Sci. 238:64-72.

Massa, G.D., H.H. Kim, R.M. Wheeler, and C.A. Mitchell. 2008. Plant productivity in response to LED lighting. HortScience 43:1951-1956.

Mol, J., E. Grotewold, and R. Koes. 1998. How genes paint flowers and seeds. Trends Plant Sci. 3:212-217.

Moni, A., A.Y. Lee, W.R. Briggs, and I.S. Han. 2015. The blue light receptor phototropin 1 suppresses lateral root growth by controlling cell elongation. Plant Biol. 17:34-40.
Morrow, R.C. 2008. LED lighting in horticulture HortScience 43:1947-1950.

Nguyen, P. and V. Dal Cin. 2009. The role of light on foliage colour development in coleus (Solenostemon scutellarioides L. Codd). Plant Physiol. Biochem. 47(10):934-945.

Nhut, D.T., T. Takamura, H. Watanabe, K. Okamoto, and M. Tanaka. 2003. Responses of strawberry plantlets cultured in vitro under superbright red and blue light-emitting diodes (LEDs). Plant Cell Tissue Organ Cult. 73(1):43-52.

Olschowski, S., E.M. Geiger, J.V. Herrmann, G. Sander, and H. Grüneberg. 2016. Effects of red, blue, and white LED irradiation on root and shoot development of Calibrachoa cuttings in comparison to high pressure sodium lamps. Acta Hort. 1134:245-250.

Pacurar, D.I., I. Perrone, and C. Bellini. 2014. Auxin is a central player in the hormone crosstalks that control adventitious rooting. Physiol. Plant. 151(1):83-96.

Pedmale, U.V., S.S.C. Huang, M. Zander, B.J. Cole, J. Hetzel, K. Ljung, P.A.B. Reis, P. Sridevi, K. Nito, J.R. Nery, J.R. Ecker, and J. Chory. 2016. Cryptochromes interact directly with PIFs to control plant growth in limiting blue light. Cell 164(1):233-245.

Peñuelas, J. and I. Filella. 1998. Visible and nearinfrared reflectance techniques for diagnosing plant physiological status. Trends Plant Sci. 3(4):151-156.

Poudel, P.R., I. Kataoka, and R. Mochioka. 2008. Effect of red-and blue-light-emitting diodes on growth and morphogenesis of grapes. Plant Cell Tissue Organ Cult. 92(2):147-153.

Sorin, C., J.D. Bussell, I. Camus, K. Ljung, M. Kowalczyk, G. Geiss, H. McKhann, C. Garcion,
H. Vaucheret, G. Sanberg, and C. Bellini. 2005. Auxin and light control of adventitious rooting in Arabidopsis require ARGONAUTE1. Plant Cell 17(5):1343-1359.

Terashima, I., T. Fujita, T. Inoue, W.S. Chow, and R. Oguchi. 2009. Green light drives leaf photosynthesis more efficiently than red light in strong white light: Revisiting the enigmatic question of why leaves are green. Plant Cell Physiol. 50(4):684-697.

Wang, Y., T. Zhang, and K.M. Folta. 2015. Green light augments far-red-light-induced shade response. Plant Growth Regulat. 77(2):147155.

Wollaeger, H.M. and E.S. Runkle. 2014. Growth of impatiens, petunia, salvia, and tomato seedlings under blue, green, and red light-emitting diodes. HortScience 49:734-740.

Wu, H.C. and C.C. Lin. 2012. Red light-emitting diode light irradiation improves root and leaf formation in difficult-to-propagate Protea cynaroides L. plantlets in vitro. HortScience 47:1490-1494.

Xue, L., Z. Wang, W. Zhang, Y. Li, J. Wang, and J. Lei. 2016. Flower pigment inheritance and anthocyanin characterization of hybrids from pink-flowered and white-flowered strawberry. Scientia Hort. 200:143-150.

Zhang, T., S.A. Maruhnich, and K.M. Folta. 2011. Green light induces shade avoidance symptoms. Plant Physiol. 157(3):15281536.

Zhou, Y. and B.R. Singh. 2002. Red light stimulates flowering and anthocyanin biosynthesis in American cranberry. Plant Growth Regulat. 38(2):165-171. 